\title{
Creativity and Translation Quality: Opposing Enemies or Friendly
} Allies? ${ }^{1}$

\begin{abstract}
In recent years, placing the translator's agency at the fore of creativity research has drawn the scholars' attention towards the need to define the role of individual personality traits in creativity in the translation process. But many questions still remain as to the role that a creative personality may play in the translation process and the final quality of translation performance. The study proposed here specifically aims to investigate the consequences of a creative profile for translation performance. The experiment correlates the scores of forty Spanish professional translators on a validated creativity personality test with their scores on product indicators of creativity. Translations were rated for accuracy and creativity by two different examiners. Results of the study suggest that creative intelligence plays a role in guiding translational behaviour, directing the translator's attention and fostering flexible thinking, but does not necessarily guarantee higher quality in terms of number of translation errors.
\end{abstract}

\section{Keywords}

creativity; creative intelligence; creative shifts; translation process; translation quality; accuracy; personality; flexible thinking

\section{Introduction}

We are in the midst of a technological golden age, in which innovation and creativity go hand in hand. In this era of open, endless innovation, businesses' ability to rethink and generate new ideas has become the key to sustain and foster global competitiveness and economic growth. Moreover, in the context of the current economic depression, creativity has regained power as an ingenious quality to fight one's way out of the crisis by effectively standing out from the competition. And the publishing and translation industries are no exception in this panorama of globalization and competitiveness. As the number of qualified translators increases, so does the need to develop creative strategies to achieve excellence and stay ahead of competitors. In their search for the best translators, publishers and translation agents look for work efficiency and quality, but also praise talent. The question arises then: are the most talented translators in pole position in the race for professional success?

This revalorization of creativity in the workplace is based on qualities that place the concept away from its mystical origins. Truth be told, most people would probably still associate creativity with a sudden flash of insight, an experience that comes as a gift given only to a few, and most probably diminished by expertise and learning. However, in current creativity research these beliefs are just popular myths (Weisberg 1993). Nowadays, creativity is mainly conceived of as an ability or capacity that every human being possesses, but that needs to be fostered and exercised

1 This research is supported by the Spanish Ministry of Economy and Competitivity (Grant FFI2013-45553-C3-3-P) and the Seneca Foundation, Regional Agency of Science and Technology (Grant 19238/PI/14).

\footnotetext{
* Ana Rojo \& Purificación Meseguer

University of Murcia

Departamento de Traducción e Interpretación

Facultad de Letras

C/Santo Cristo, 1. 30001. Murcia

anarojo@um.es-purificacion.meseguer@um.es
} 
in order to become useful and predictable (Boysen 2015). In Pablo Picasso's words "Every child is an artist, the problem is staying an artist when you grow up". Behind every creative idea is a tortuous process guided by many small ideas that may at times get discarded, but at others lead to a great new one. The ability to drive along this creative path can be nurtured through training, hard work and discipline-specific expertise (Baer 2015).

There is now plenty of evidence documenting that expertise is a pre-requisite for creativity (Ericsson 1998; Reilly 2008). This assumption posits that creativity needs to rely on expert thinking skills and that mastering a given domain is necessary to produce something new and valuable. From this perspective, research on creativity implies the definition of those techniques and abilities involved in expert performance within a particular discipline or domain. Needless to say, accepting the link between expertise and creativity should not rule out particular cases that prove the ingenuousness of taking the benefits of expertise for granted (see, e.g., Frensch/Sternberg 1989). Besides real-life cases of entrepreneurs without previous business experience who have succeeded in a certain field and achieved recognition as creative individuals - e.g., Thomas Edison, Walt Disney, Coco Chanel or Steve Jobs ${ }^{3}$, to mention just a few - there is also empirical evidence showing that expertise may sometimes inhibit creativity. While inexperienced individuals may benefit from explorative behaviour, experts may display more conventional thinking and resort less often to experimentation (Wiley 1998).

This article attempts to explore the relationship between expertise and creativity within the context of translation. The double-sided nature of translation as a professional activity and an artistic task - i.e., a task involving a certain degree of imagination and ingenuity, especially in the case of literary translation - points to it as a suitable candidate to investigate the benefits of creativity for translation performance (see Perteghella/Loffredo 2006). For this purpose, we conduct an experiment that explores the relationship between creative intelligence and translation creativity understood as a quality of the translation product resulting from expert performance.

\section{Challenges in defining and researching creativity}

Creative intelligence and innovative skills are two prime movers of economy in the modern world, where they have become de rigueur for personal and professional success. But despite the worldwide recognized excellence of creativity, research on this area still lags behind others. Part of the blame for the scarcity of research results is attributed to the emotional component of creativity, often identified with inspiration as some mythical spark of genius. The bond traditionally assumed between creativity and genius eventually unveiled a dark side of creativity, linking it to mood disorders and pointing to its potential as an impending risk for successful performance. As a result, creativity research was somehow driven to the background in psychology and went long unnoticed in other areas (Batey/Furham 2006). ${ }^{4}$

But most of the blame for this research lag lies in the problems to define and operationalize the concept for measurement. The plain fact is that creativity is too elusive and complex to be precisely defined. For one thing, there is the controversy previously mentioned around its innate or learnt nature: is creativity a gift given at birth or a skill that can be acquired later on in life and trained through practice? For the other, researchers must also face its threefold nature as a participant-, product-, and process-component. Creativity is found both in creators and in their creations,

2 Quote attributed to Pablo Picasso. It appeared as an epigraph at the beginning of the article "Modern Living: Ozmosis in Central Park", published on October 4, 1976 in Time magazine.

3 A summary of how these entrepreneurs started a business without much money or previous experience can be found in https://smallbiztrends.com/2016/03/successful-entrepreneurs-with-no-experience.html

4 There is also evidence suggesting that the pervasiveness of the dual nature of creativity has prevailed up to the present day. Hence, recent data have been provided on people's ambivalent attitudes towards creativity, demonstrating that under conditions of uncertainty, people tend to link creativity with words with negative implicit associations, such as "vomit", "poison" or "agony" (Mueller et al. 2010). 
which brings forth the need to measure the individual's creative potential as well as assessing the creative features found in their creations and in the process leading to these.

This multidimensional nature of creativity is also related to the debate on whether it is a domain-general or specific trait. Thus, those who argue that creativity is a domain-general trait sustain that people who are creative in one field are also likely to be creative in other areas. This approach envisions creativity as a personal trait similar to intelligence, relating its study to the psychometric study of individual differences. In contrast, those who argue that creativity is domain-specific make a case for people having "islands of creativity" - that is, spaces or areas where they can be highly creative - in contrast to domains where they may not be creative at all. This approach addresses creativity from the point of view of the creation process and the context where it occurs, relating it to socio-cultural and problem-solving theories (see Silvia et al. 2009).

In domains where creative performance is still ill-defined - as in the case of translation - this threefold nature of creativity leads to an assessment dilemma: what is actually a better indicator of creativity, the individual's levels of creative intelligence or their product and process features? Since placing the focus on the individual involves working with psychological tests that may seem out of reach to many translation scholars, so far creativity research in translation has mainly focused on identifying the procedures and techniques that define creative behaviour in the translation product. But placing the focus on the product still poses the problem of the researcher's subjectivity in identifying markers of creativity: what are the indicators of creativity processes in translation? How can we measure novelty? How can processes such as divergent or flexible thinking be measured in translation? And last but not least, do high levels of creative intelligence always ensure a quality translation? Moreover, if we assume the domain-specificity of creativity, then it seems logical to presuppose that creativity will take different forms in the different types of specialized translation, pointing to the need to define creativity in relation to the particular translation domain under research.

In the study included in the present article, we propose to triangulate data from both product and process assessment methods, using a psychometric measure of creative intelligence as a potential predictor of creative processes in translated texts. The test used - the Spanish Creative Intelligence Test - CREA (Corbalán et al. 2003) $)^{5}$ measures creative intelligence primarily in terms of divergent thinking, that is, the ability to produce varied original ideas. Rather controversial is still the question of whether or not creativity is related to intelligence. Although there is evidence for and against the relationship between intelligence and creativity, most influential models of intelligence assume nowadays a substantial correlation between creativity and intelligence, treating creativity as a lower order factor of intelligence - whether it is considered as the ability for retrieval, imaginativeness or divergent production (see Jauk et al. 2013). Despite the fact that Guilford's (1956) constructs of divergent thinking and convergent thinking have been traditionally associated with different abilities - divergent thinking with creativity and convergent thinking with intelligence - in recent years, literature on creative cognition has claimed that both modes of thinking are necessary to provide a comprehensive view of human problem-solving processes. Convergent and divergent abilities are assumed to be intertwined and interact especially in those processes that result in original and appropriate solutions within a specific context (see Jaarsveld/ Lachmann 2017). The assumption for using the CREA test in our experiment is that divergent thinking is a component of creative intelligence and performance; therefore, assessing the individuals' potential for divergent thinking can serve to identify the processes and techniques developed in their specific domain of expertise. Nevertheless, it is important to bear in mind that despite our genetically established potential for creative intelligence, the environment also determines the extent to which we realize our potential by improving our skills. Thus, evidence shows not only that people can be taught to think more creatively (see, e.g., Stenberg 2010), but also that

5 The validity of the CREA test for assessing divergent thinking has been supported in a variety of studies (see Clapham/King 2010 for reference to validation of the CREA test). 
creative performance may be linked to domain-specific expertise. In this sense, Baer (2015: 166) compares one's creative potential and creative performance to:

a cook who has an extensive spice rack and knows how to use it. It isn't that she uses the same spice in every dish. Her expertise, and her creativity, are linked to having many different spices at her disposal and figuring out which spices will work best in which dishes.

\section{Creativity in Translation Process Research (TPR)}

TPR studies on creativity are still rather scarce, but some interesting data are already available. Some of the reasons for the paucity of creativity research are probably its link to the emotional side of the brain as well as TPR scholars' early focus on an information-processing paradigm of cognition. The traditional separation between reason and emotion long permeating Western scientific thinking has also drawn scholars' attention towards the more rational part of the brain and relegated emotional processes to a secondary role. In translation, for instance, process research studies have for the most part adhered to this information-processing paradigm, focusing on the logical side of the brain through the study of attention and memory, or the role of problem-solving and decision-making processes, among other things.

But current research in psychology and neuroscience has brought forward a new embodied view of the mind (Damasio 1994, 2010), according to which the body is now envisioned as part and parcel of normal cognitive processes, and emotions as a key component of reason and decision-making. In recent years, TPR researchers have also started to depart from the purely rational and logical view of cognition, gearing research toward a more embodied view that emphasises the most human, social, and cultural dimensions of cognition. Mainstream topics, such as problem-solving or decision-making processes, are still investigated, but a door is opened to psychological, emotional, and social factors. In line with Damasio's view, decision-making is conceived of as a cognitive operation governed by emotional factors, an assumption that paves the way for researching the role of emotions and creativity in the translation process.

By the end of the twentieth century, the acknowledgment of translation as a problem-solving activity pointed to the need to define the processes and strategies associated with creativity in translation. Moreover, the view that translation problems inherently require a great deal of creativity contributed to expanding creativity research to typically process related areas, such as the relationship between creativity and experience, the relationship between a creative personality and successful translation performance, and the impact of creativity on cognitive - mostly problem-solving - processes. In what follows, we will summarise the main results from each of these areas that are of relevance for the present research.

Existing work on the relationship between creativity and experience is not conclusive yet. Whereas there are data that point to professionals being more creative than students - especially in coping more effectively with problems (see, e.g., Riccardi 1998) - more recent results, such as those from Tiselius and Jenset (2011) in interpreting studies, suggest that creativity may even decrease with experience and that more experienced interpreters tend to overgeneralise to a greater extent than less experienced ones. In written translation, work by Rojo and Ramos (2016) explores the influence of different types of feedback on creativity in both novices and expert translators. Their data point to the beneficial effect of positive feedback on creativity in both novices and professionals, although the effect seems to be stronger in students, who show higher levels of improvement. Negative feedback also seems to have a beneficial effect on accuracy in both novices and professionals, although the improvement among professionals is significantly greater. In addition, evidence has also been provided pointing to a promising effect of expertise on participants' reported levels of creativity. Thus, work by Ramos and Rojo (2016) has suggested that work experience may lead to an increase in creativity, at least in certain areas, such as audio description. Their work with audio descriptors revealed a significant positive correlation between 
years of professional experience in audio description and greater creativity scores in the CREA test for creative intelligence.

When placing creativity at the fore of TPR, attention must be somehow shifted to the translator as the ultimate performer of those processes. Probably due to the problems involved in measuring creativity, most personality-oriented research on translational creativity has focused on the exploration of individual traits frequently associated with creativity. Two of the personality traits most frequently correlated with creativity are intuition and emotional intelligence. In translation, Hubscher-Davidson's $(2009,2013 \mathrm{a}, 2013 \mathrm{~b}, 2013 \mathrm{c})$ work has pioneered the exploration of the role of these two personality traits in the translation process. Results from her work hint at a correlation between successful levels of performance in literary translation and the presence of an intuitive trait among translation students, measured by the Myers-Briggs Type Indicator (MBTI) questionnaire. Similarly, her data on emotional intelligence also suggest the existence of a correlation between high levels of emotional intelligence and successful performance. Other personality traits related to creativity that have been explored in interpreting studies are those of self-efficacy, negative affectivity, and self-esteem ${ }^{6}$. Results indicate that the competence of sign language interpreters is positively correlated to personality traits related to organisational capacity, such as goal orientation and self-efficacy, but negatively correlated to negative affectivity (Bontempo/Napier, 2009, 2011; Bontempo et al. 2014).

Regarding the role of creativity on problem-solving processes, existing evidence links creativity to flexible and fluid thinking, and to the capacity to adopt broad-based strategies to tackle problems in a novel way. In translation studies, Guilford's (1950) nine psychological dimensions of creativity have been generally summarised into the three most prototypical ones, namely, those of flexibility, novelty and fluency, plus the dimension of acceptability, added by Bayer-Hohenwarter $(2009,2010,2011,2013)$ as necessary to define the adequacy of translations. To date, she has provided the most detailed and extensive method to measure creativity in translation based on those dimensions. Thus, acceptability is reflected in the absence of errors, flexibility in the use of translation shifts - now defined in Kussmaul's (2000a, 2000b) sense of cognitive operations - novelty in the presence of unique solutions, and fluency in routine behaviour. In her model, flexibility is the core indicator of creativity and is reflected in three main types of obligatory translation shifts representing directions of thinking (i.e., abstraction, modification, and concretisation), and in a set of optional shifts that depart from literal translation even when literalness is an acceptable solution. Interestingly, her research suggested that successful performance is not necessarily defined by a high proportion of creative shifts, but by "the ability to decide efficiently when to use a creative shift and when a mere reproduction is sufficient" (Bayer-Hohenwarter 2011: 686). Results from her research suggest that successful translators achieve a cognitively efficient balance between flexible problem solving and routinized reflex.

In connection with the role of creativity on translation and problem-solving processes, we also find results pointing to an impact of creativity on processing time. For instance, Heiden (2005) provided evidence in favour of long revision phases being a strong indicator for creative translation processes. In psychological studies, there is also evidence, such as that by Vartanian et al. (2007), reporting that more creative participants - as determined by a series of psychometric tests - achieved shorter reaction times when the task they were asked to perform did not demand the inhibition of interfering information (e.g., as in tasks involving negative priming), but displayed longer reaction times on tasks that involved some sort of interference. More creative participants were, therefore, faster when distraction was minimal and the task allowed maximal focus of attention, but slower when inhibitory interference was maximal and they had problems to focus their attention. This result suggests that creativity is related to the ability to distribute attention efficiently. Further evidence on the relationship between creativity and attention also points to

6 For more information on the relationship between creativity and self-efficacy, negative affectivity, and self-esteem, see, e.g., Jaussi et al. 2011, Akinola/Mendes 2008, Gerrard et. al. 1996 or Cifuentes Férez/Fenollar Cortes 2017. 
the effect of task complexity on processing time. Thus, results from Oakley (1996) revealed that participants' ability to narrow or widen their attention seems to depend on the nature of the task: tasks demanding widened apertures increase response time while those involving narrowed apertures decrease it.

In the next section, we will introduce a study designed to explore the role of creativity in four of the aspects already reviewed: the analysis of translation shifts as indicators of creative strategies, the measurement of translators' levels of creative intelligence, the analysis of the relationship between creativity and work experience and the impact of creativity on time.

\section{The Study}

\subsection{Aims and Hypotheses}

The present study introduces an experiment exploring the impact of translators' levels of creative intelligence on translation quality in expert performance. The study aims to test the correlation between the psychometric measurement of the translators' levels of creative intelligence and potential indicators of translation quality. The psychometric measure was obtained by using the Spanish Creative Intelligence Test - CREA (Corbalán et al. 2003). Quality indicators were analysed for both the accuracy and creativity of the translation product, where accuracy was measured in terms of number of mistakes or inadequate solutions, and creativity in terms of the strategies reflecting flexible and novel thinking. Additionally, the study also aimed to test the correlation between the translators' levels of creative intelligence and two other indicators of expert performance, namely, the time required to complete the translation and their years of experience in the profession.

Based on the results provided in the existing literature, the following four hypotheses summarise the predictions made to test the previous aims:

1. There will be a negative correlation between CREA scores and number of accuracy mistakes. So, the higher participants score in the creative intelligence test, the lower the number of accuracy mistakes in their translations.

2. There will be a positive correlation between CREA scores and number of creative shifts and degree of novelty. Thus, the higher they score in the creative intelligence test, the higher the number of creative shifts they will use in their translations and the greater the degree of adequacy and novelty of the translation solutions provided.

3. There will be a positive correlation between CREA scores and overall translating time. The higher participants score in the creative intelligence test, the faster they will complete their translation.

4. There will be a positive correlation between CREA scores and years of experience. Those participants with more years of translating experience will score higher in the creative intelligence test.

\subsection{Participants}

Forty professional translators took part in the study. They were recruited online with a message requesting participation in a research project. Their age ranged between 23 and 59 years with a mean age of 36.6 years old, and there were 12 males and 28 females. All the participants had a minimum of 1.5 years' work experience translating literary and technical texts. The maximum years' work experience was 30 with a mean experience of 9.7 years. Given the problems to find volunteers, professional translators were offered payment for their participation. 


\subsection{Design and Materials}

As already mentioned, to measure the participants' creativity, we used the Spanish Creative Intelligence Test - CREA (Corbalán et al. 2003). The simplicity of the test facilitated the experimental procedure, since participants are given an image and are requested to formulate as many questions as possible during four minutes (see Appendix 1).

The text to be translated was an extract of roughly 300 words taken from Terry Pratchett's novel Witches Abroad (1991) (see Appendix 2). The text had a clear pragmatic function - it was patently ironic and humorous - and included units that demanded highly creative solutions, e.g., a linguistic play on words and a cultural translation problem.

\subsection{Procedure}

Participants were not informed of the final purpose of the experiment. Volunteers were requested via e-mail to participate in an experiment on the translation process. They were informed that they would receive payment for their participation and that the task could be performed in their habitual work environment. Specific and detailed instructions were provided to complete the three phases of the experimental design.

Firstly, participants were asked to sign an informed consent form, in which they agreed to participate in the experiment. They could withdraw at any time. Once the consent form was signed, they were requested to fill in a brief personal and professional data questionnaire, and complete a psychological profile test: the Spanish Creative Intelligence Test - CREA. They were given detailed instructions on how to do the test.

Secondly, participants were informed of the need to translate the text that they had received from English into Spanish. They were told to write down the starting and finishing times of their translation. After completing the whole experiment, they sent all the files to an email address created for the study.

The creativity test was corrected on the advice and guidance of a team of specialised psychologists ${ }^{7}$. The evaluation procedure of the translations involved two blind external examiners. They were both teachers at the Translation and Interpreting Degree at the University of Murcia, and one of them also had professional experience as a literary translator. The two of them had taught on the same subjects before and agreed on evaluation methods. The two examiners were given specific instructions to rate the translations for overall performance and the different parameters specified in the evaluation sheet provided (see Appendix 3). The final mark was the mean score of the two.

\subsection{Analysis of Results}

\subsubsection{Rating Method}

To analyse our results, levels of overall performance, creativity and accuracy needed to be operationalised into a set of measurable parameters. To this purpose, the correction sheet shown in Appendix 3 was designed to rate the translations for accuracy and creativity. Accuracy was measured in terms of detected number of errors, by subtracting points from the overall mark ${ }^{8}$. The number of points subtracted ranged from -0.25 to -1 depending on the type of error and their relative weight on the whole translation. In contrast, creativity was measured by awarding them points for indicators of flexibility, novelty and fluidity. The number of points awarded ranged from +0.5 to +2 depending also on the type of solution and their relative weight on the whole translation.

7 This team was composed of one of the designers of the CREA test, Javier Corbalán Berna, PhD in psychology from the University of Murcia (Spain), and two other specialists in creativity and personality, Olivia López Martínez and Eugenia Piñero Ruiz, both PhD in psychology from the University of Murcia.

8 For more information on the controversy around translation evaluation and accuracy see e.g. Nord 1977. 
Overall accuracy was rated in terms of three general parameters or variables for testing it: transference of meaning, transference of pragmatic function, and correctness of target text. Accuracy errors in the transference of meaning included false meanings, opposite or incoherent meaning, and unnecessary omissions or additions of meaning. Errors in the transference of pragmatic function comprised the loss of cultural references, implied meaning and pragmatic function. Errors in the correctness of target text included grammatical and spelling mistakes.

In contrast, points were awarded for indicators of both creative flexibility and novelty, that is, translations were given points for unique solutions and for indicators of creative shifts. Following Bayer-Hohenwarter, shifts were classified either as primary or secondary. In very general terms, primary shifts involved semantic changes in the level of abstraction; they included three main types: abstraction, that is, when translators used a more general term or expression; concretisation, when they used a more specific one; and modification, when they used other variants that modified the level of abstraction. Secondary changes were optional and included four types: explanation, or making information contained in the ST explicit; emphasising, in which some element was included adding a new value; change of perspective, which included traditional modulation and transposition; and enrichment, which added a metaphor or any other original contribution to meaning. A range of points was established for novel solutions according to their frequency of occurrence, with unique solutions receiving the highest mark $(+2)$, those found in less than ten percent of the cases being given half the mark $(+1)$, and those found in less than fifty percent of the cases receiving the lowest score $(+0.5)$.

\subsubsection{Statistical Methods}

Basic descriptive statistical methods were first used to analyse the variables. For qualitative variables, absolute and relative frequency measures were obtained; for quantitative variables, maximum and minimum percentage, mean and standard deviation. The Spearman correlation test was used to examine the relationship between the variables. Statistically significant correlations showed $\mathrm{p}$ values below $0.05(\mathrm{p}<0.05)$. The tables provided below display the values for Spearman's rank correlation coefficient or Spearman's rho $\left(r_{s}\right)$. A perfect Spearman correlation can range from -1 to +1 . Those values indicating a statistically significant correlation are marked with an asterisk.

\subsubsection{Hypothesis 1}

Our first hypothesis predicted a negative correlation between creativity scores and number of mistakes, that is, we assumed that the higher the creativity score, the less number of errors in translation accuracy. But, as shown in Table 1, no significant correlation was found between the participants' creativity scores and their number of errors.

\begin{tabular}{lcccc}
\hline & \multicolumn{4}{c}{ ACCURACY } \\
\cline { 2 - 5 } & Meaning & Pragmatics & Correctness & TOTAL \\
\hline CREA Test & -0.07 & 0.08 & 0.09 & -0.02 \\
Time & -0.01 & 0.08 & 0.06 & 0.03 \\
Years of experience & 0.12 & 0.01 & 0.19 & 0.14 \\
\hline
\end{tabular}

Table 1. Correlations between the accuracy variables and the CREA test, translation time and years of experience

The lack of a correlation between creativity scores and number of mistakes suggests that creative intelligence may not serve as a good predictor of accuracy. Although creativity is mostly associated with successful performance, a plausible explanation for the lack of results is that this suc- 
cess may be conditional upon the type of processing required by task demands, or at least upon the participants' perception of these demands. On the one hand, it is possible that the participants' creativity has no impact on accuracy because each aspect involves different processing abilities. Accuracy draws attention to item-specific processing, which requires, for the most part, a narrow focus of attention, while creativity is frequently related to defocused attention and a tendency to divergent thought. On the other, it is also possible that the lack of results can be attributed to the participants' perception of task demands. Thus, even if assuming that creativity involves the ability to narrow or broaden the scope of attention according to situational demands (see Gabora 2010: 5 ), there is the possibility that the participants' perception of task demands voluntarily placed creative translation problems in the foreground and formal accuracy in the background.

Even if it was outside the scope of our predictions, correlations between accuracy and time and years of experience were also tested (see Table 1 above). Surprisingly, no positive or negative correlations were reported either. It seemed that neither the time used to carry out the translation, nor the years of translating experience could be used as predictors of mistakes. Since no time constraints were imposed and all participants were already professional translators, no definite conclusion can be drawn from this lack of correlations.

\subsubsection{Hypothesis 2}

Our second hypothesis predicted a positive correlation between creativity scores and number of creative shifts and novel solutions, that is, we assumed that the higher the participants' score on the creative intelligence test, the higher the number of shifts they would adopt and the more adequate and novel their solutions would be.

This hypothesis was only partially confirmed, since a positive correlation was reported with primary shifts (see Table 2 and Graph 1 below), but not with secondary ones (see Table 3) or with novelty (see Table 3).

\begin{tabular}{|l|c|c|c|c|}
\hline & \multicolumn{4}{|c|}{ PRIMARY SHIFTS } \\
\hline & Abstraction & Concretisation & Modification & TOTAL \\
\hline CREA Test & -0.10 & NR & $0.34^{*}$ & $0.32 *$ \\
\hline $\begin{array}{l}\text { NR: Non realizable. Constant value variables. } \\
\text { * Statistically significant result. }\end{array}$ \\
\hline
\end{tabular}

Table 2. Correlations between creative primary shifts and the CREA test, translation time and years of experience

As shown in Table 2, a statistically significant correlation was found between the participants' scores for creative intelligence and their use of primary shifts $\left(r_{s}=0.32\right)$. More specifically, the correlation was found in their use of modification shifts $\left(r_{s}=0.34\right)$, a strategy that points to the use of synonyms modifying the level of abstraction of the source text term. Graph 1 below illustrates this correlation and the distribution of the participants: 


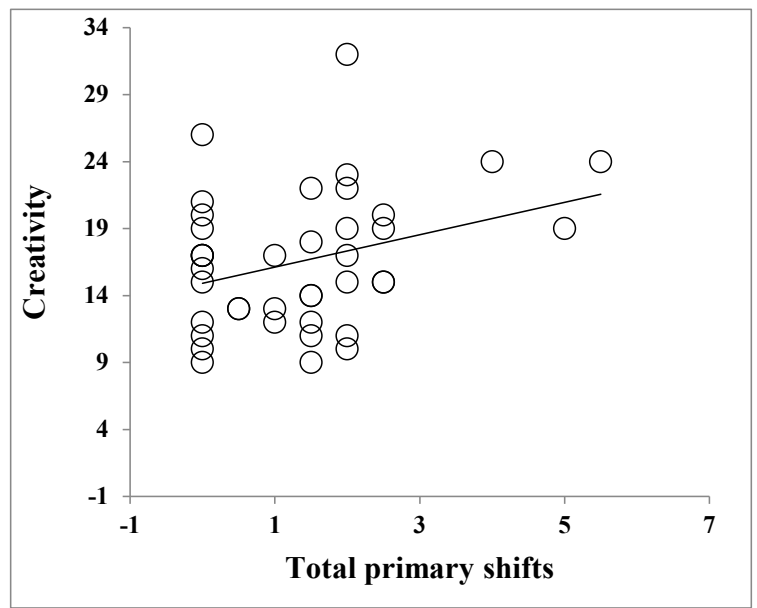

Graph 1. Correlations between creative primary shifts and the CREA test.

To check on the adequacy of the solutions provided, the translations by the 10 participants with the highest creativity scores and those by the 10 with the lowest were analysed. This qualitative analysis of some of the main translation problems actually revealed differences in the participants' quality performance. For instance, the main translation problem involved rendering the name of the mountain (Bear) and reproducing the play on words between the senses of bear and bare. Those participants who attempted to reproduce the play on words looked for synonyms that sounded similar enough as to cause the confusion. However, those with the lowest creativity scores selected pairs of words that were not similar enough at a formal level as to be misunderstood, or not likely enough to be found in a mountain or associated with one, such as oso-osaba (lit. 'bear-dare'); oso-oca (lit. 'bear-goose'); oso-ósea (lit. 'bear-bony'). In contrast, those with the highest creativity scores chose words that were more similar on formal grounds, and more likely to be in a mountain or being used to describe one, such as oso-foso (lit. 'bear-pit'). Some even changed the name of the mountain, creating a new play on words with a bear-related quality (e.g. Montaña de los Pardos-osos pardos (lit. 'Mountain of the Brown-brown bears').

However, as displayed in Table 3, no significant correlation was found between the CREA scores and the number of secondary shifts $\left(\mathrm{r}_{\mathrm{s}}=0.14\right)$.

\begin{tabular}{|l|c|c|c|c|c|c|c|c|}
\hline & \multicolumn{5}{|c|}{ SECONDARY SHIFT } & NOVE. & TIME & EXPER. \\
\hline & Explan. & Emphat. & $\begin{array}{c}\text { Change of } \\
\text { perspective }\end{array}$ & Enrich. & TOTAL & TOTAL & TOTAL & TOTAL \\
\hline $\begin{array}{l}\text { CREA } \\
\text { TEST }\end{array}$ & 0.28 & -0.05 & 0.15 & 0.05 & 0.14 & 0.01 & 0.14 & -0.11 \\
\hline TIME & & & & & & & & $-0.36^{*}$ \\
\hline
\end{tabular}

Table 3. Correlations between scores on the CREA test, creative secondary shifts, novelty, time on task and years of experience

Two possible explanations for the lack of results with secondary shifts could be the difficulty of the translation problems posed in the text and the translators' need to comply with literary translation conventions. Let us take once again the play on words as an example. Given the impossibility to translate the source text words literally into Spanish, instead of trying to reproduce an equivalent play on words, some participants (10 out of 40) opted for providing an explanation within the text, or in a translator's note, most probably in an attempt to preserve the intent of the source text author. It may be possible that an explanation of the original play on words was perceived as 
more adequate to genre conventions than a more creative reproduction. The translator's note was slightly more common in the translations by those participants with the lowest creativity scores ( 3 out of 7) but, contrary to our expectations, it was also the option of some of the most creative participants (2 out of 7).

No significant correlation was found either between the CREA scores and the degree of novelty of the solutions adopted $\left(\mathrm{r}_{\mathrm{s}}=0.01\right)$. This result could be somehow related to the previous one, since participants resorted to the translator's note, regardless of their creativity levels, possibly in the already mentioned attempt to preserve the source text author's intent. Nevertheless, the effects of participants' perception of task demands on creativity could be further explored by explicitly instructing participants to be original. There is in fact psychological evidence suggesting that creative people's performance is mostly enhanced when they are explicitly instructed to be original (Martindale/Hasenfus 1978).

Moreover, there is also the possibility that the way adopted to measure novelty was not the most appropriate one. Let us remember that points were awarded for three different degrees of novelty by comparing the solutions produced by the different participants. However, considering that the options were very limited by both contextual and linguistic factors, the variety of the solutions provided was extremely constrained.

\subsubsection{Hypotheses 3 and 4}

Our third hypothesis predicted a negative correlation between the participants' creativity scores and the time they used to complete their translations. But, as shown in Table 3 above, no statistical significance was reached $\left(r_{\mathrm{s}}=0.14\right)$.

Despite the lack of statistically significant results, participants with higher creative potential generally took longer to complete the translation task than participants with lower creative potential. In the light of existing results, a plausible explanation could be found in the complexity of translation as a task that does not allow participants to easily narrow their attention. Rather, the translation process may demand a continuous inhibition and selection of information that is more likely to call for widening of attention. As pointed out by Oakley (1996), individuals' narrowing or widening of attention seems to depend on the nature of the task and widened apertures increase response time.

Finally, our fourth hypothesis predicted a positive correlation between the participants' length of professional experience and their creative intelligence scores, assuming the possibility that greater experience in literary translation could serve as a predictor of creative abilities. This time the tendency revealed a negative correlation - that is, the shorter the experience, the higher the CREA score - but no statistical significance was reached either $\left(r_{s}=-0.11\right)$. A plausible explanation for this result could be found in the fact that most of our participants' work was not exclusively focused on literary translation; a big majority did actually work also in other fields.

Even if outside the scope of the study, our data did yield a significant correlation between years of experience and the time employed to complete the translation, that is, the longer the experience, the faster they translated (see Graph 2). Greater experience is not necessarily a predictor of less mistakes, but it can serve as a predictor of the time needed to complete the translation. This result seems to support previous findings on TPR studies relating experience to time (see, e.g., Dragsted et al. 2009 or Tiselius/Jenset 2011). 


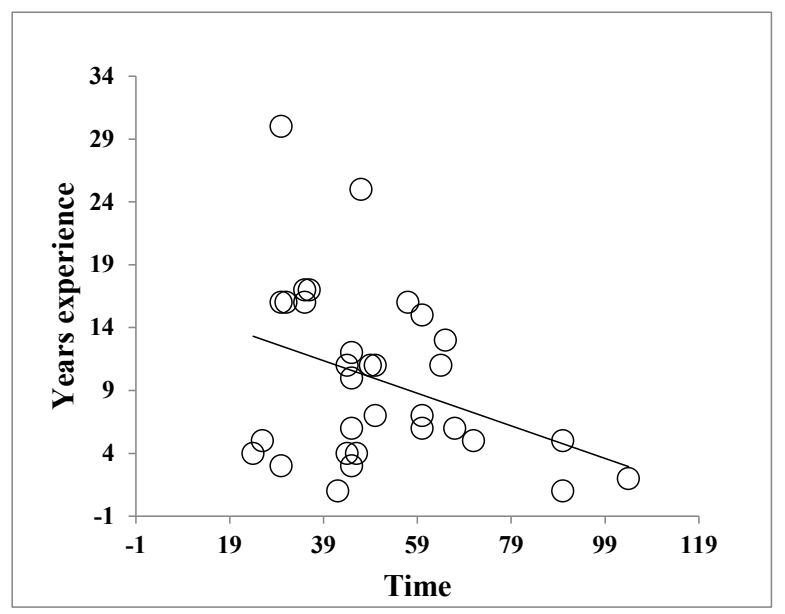

Graph 2. Correlation between years of experience and time.

\section{Conclusions}

The idea of translation as a mechanical, straightforward task is a widespread folk myth. There is a myriad of real life examples of translations showing traces of translators' creativity. Not even technical translation can be at all times reduced to a hundred percent literal rendering of meaning. Skilled translators usually infuse a sound dose of creativity into their translations. The catch is that to be effective - that is, to achieve a quality translation - the dose has to be adjusted to stay within an optimal range. And this is the crux of the matter that this study aimed to answer: what defines such an optimal range in translation?

Existing results - such as those provided by Bayer-Hohenwarter's work - have related successful performance in translation to the efficient balance between flexible problem solving and routinized reflex. But no clear attempt has been made yet to account for the role of the translator's creative capacity. The present study intended to cast some light on the issue by departing from the assumption that this balance or optimal range requires the adjustment of the translator's creative capacity to the specific demands of the translation task. However, our results are still far from being conclusive. On the one hand, our data suggest that translators' creativity scores cannot be used as predictors of translation quality. A high score on creativity does not necessarily correlate with a lower number of errors. But on the other hand, our data point to a possible relationship between creativity scores and flexible thinking - defined here as the ability to use specific translation strategies or shifts. The higher the score, the greater the use of the main types of primary or obligatory translation shifts, and the greater the tendency towards more adequate solutions. Nevertheless, it is still somewhat early for rejoicing, since the relationship is not so obvious; alas, no correlation was found with secondary or optional shifts, or with novelty.

Possible explanations for this lack of results may include problems with the experimental materials, such as the psychological test used or the text chosen to be translated, or even factors relating to the strength of the impact from the translators' creativity levels. Firstly, there is the possibility that the CREA test is not an effective predictor of the type of creativity involved in translation. Although the test is validated and has been successfully used in different professional areas, it is possible that it does not measure verbal aspects that may be essential in translation. Secondly, it could also be that the prominent humorous and pragmatic nature of the text selected to be translated forced translators to depart from the original or resort to the translator's note, making it harder to establish a clear difference between those opting for a more literal translation and those adopting a more original one. Thirdly, the complexity of the rating method could also be affecting results; even though attempts were made to diminish subjectivity by double marking, evaluators continually reported problems to decide on the type of shift involved. And finally, there is also 
the possibility that creativity scores only have a clear impact on translators with very high or very low scores on the CREA test.

In our data no statistically significant correlation was found either between scores on the CREA test and the total time reported to carry out the translation. However, the tendency reported signals to participants with higher creative potential taking longer to complete the translation task than participants with lower creative potential. Although much of the existing evidence focuses on the relationship between creativity and processing speed, time on task may also be influenced by the individual's creativity levels. A plausible explanation for the lack of statistically significant results could be found in the complexity of translation as a task that does not allow participants to easily narrow their attention. Nevertheless, further process research is needed to establish the influence of creativity on speed in more specific indicators of cognitive processing, such as duration and number of pauses, or even eye movements.

Similarly, our results do not point to a significant correlation between experience and creativity, at least in terms of the participants' creative intelligence levels. The lack of correlation between scores on the CREA test and years of experience seemed to suggest that the participants' professional experience is not related to their creative abilities. A logical explanation for this lack of correlation could be the fact that our participants' professional experience did not involve, for the most part, a high degree of creativity, since most of them also worked very often with technical texts, without a clear specialisation in literary translation. But there is also the possibility that the participants' domain knowledge actually placed them at a disadvantage, promoting fixation in their creative problem-solving attempts (Wiley 1988). From this point of view, their knowledge of literary translation conventions may have acted as a mental set, gearing their decisions towards the use of the translator's note as a convenient strategy to transmit the source text author's style.

In summary, results from our experiment indicate that creativity alone does not seem enough to ensure success in a translation task. Our data suggest, though, that it may serve to predict some aspects of translators' performance, at least in terms of the creative shifts employed. The reported correlation between creativity and primary shifts points to a relationship between creative personality and flexible thinking, but further process research is needed to define the scope of this relationship more precisely. Future research should then be conducted employing translation process research methods such as keystroke logging programs or eye-trackers. Moreover, different tests should be used to provide a more accurate and encompassing measurement of creativity potential. Lastly, the revision and refinement of the translation marking method should also be a part of the future investigation, measuring the impact of creativity on routine translating as well.

Data from this experiment do not shed perhaps as much light on the role of creative abilities in translation as one would like. The reported lack of correlation between the participants' levels of creative intelligence and most of the variables analysed suggests that translators' creativity potential on its own is not an infallible predictor of successful performance in a translation task. The trick seems to be in the translators' skill to adjust their capacity to the perceived demands of the task, injecting the dose required to achieve an optimal level. Whatever creativity potential an individual may have, they also have the ability to manage it more or less efficiently. The size of the optimum dose will vary in the different translation domains, depending on the specificities of the task and on translators' perception of these demands. On the whole, the complexity of translation demands a continuous inhibition and selection of information that is expected to call for widening of attention. Because of creative people's assumed defocused attention, placing the focus on a problem with creative potential may usually involve defocusing other aspects, such as formal correctness. When engaging in literary translation, translators are more likely to focus their attention on those aspects with a creative potential, whereas technical translation probably allows for a greater degree of routinized reflex. Needless to say, the final amount of dose instilled into the translation will ultimately depend on the translators' personal creativity skills and their ability to develop them in a particular domain by adjusting their potential to the field demands. 


\section{References}

Akinola, Modupe/Mendes, Wendy Berry 2008: The dark side of creativity: Biological vulnerability and negative emotions lead to greater artistic creativity. In Personality and Social Psychology Bulletin 34:2, 1677-1686.

Baer, John 2015: The importance of domain-specific expertise in creativity. In Roeper Review 37:3, 165-178.

Batey, Mark/Furnham, Adrian 2006: Creativity, intelligence, and personality: A critical review of the scattered literature. In Genetic, Social, and General Psychology Monographs 132:4, 355-429.

Bayer-Hohenwarter, Gerrit 2009: Translational creativity: How to measure the unmeasurable. In Göpferich Susanne/ Jakobsen, Arnt Lykke/Mees Inger (eds.), Behind the Mind: Methods, Models and Results in Translation Process Research: Copenhagen Studies in Language. Copenhagen: Samfundslitteratur, 39-59.

Bayer-Hohenwarter, Gerrit 2010: Comparing translational creativity scores of student and professionals: Flexible problem-solving and/or fluent routine behaviour? In Göpferich Susanne/Alves, Fabio/Mees, Inger (eds.), New Approaches in Translation Process Research. Copenhagen Studies in Language. Copenhagen: Samfundslitteratur, 83-111.

Bayer-Hohenwarter, Gerrit 2011: “Creative shifts" as a means of measuring and promoting creativity. In Meta 56:3, 663-692.

Bayer-Hohenwarter, Gerrit 2013: Triangulating translational creativity scores: A methodological study in translation process research. In Way, Catherine/Vandepitte, Sonia/Meylaerts, Reine/Bartlomiedjczyk, Magdalena (eds.), Tracks and Treks in Translation Studies. Amsterdam/Philadelphia: Benjamins, 63-86.

Bontempo, Karen/Napier, Jemina 2009: Getting it right from the start: Program admission testing of signed language interpreters. In Angelelli Claudia/Jacobson, Holly (eds.), Testing and Assessment in Translation and Interpreting. Amsterdam, The Netherlands/Philadelphia, PA: Benjamins, 247-295.

Bontempo, Karen/Napier, Jemina 2011: Evaluating emotional stability as a predictor of interpreter competence and aptitude for interpreting. In Interpreting 13:1, 85-105.

Bontempo, Karen/Napier, Jemina/Hayes, Laurence/Brashear, Vicki 2014: Personality matters: An international study of sign language interpreter disposition. In International Journal of Translation and Interpreting Research 6:1, 23-46.

Boysen, Mikkel Snorre Wilms 2015: Does creativity rely on expertise? In Carmo, Mafalda (ed.), Education Applications \& Development: Advances in Education and Educational Trends. Portugal: inScience Press, 122-130.

Cifuentes Férez, Paula/Fenollar Cortes, Javier 2017: On the impact of self-esteem, emotion regulation and emotional expressivity on student translators' performance. In Vigo International Journal of Applied Linguistics 14, 71-97.

Clapham, Maria/King, W. Ryan 2010: Psychometric characteristics of the CREA in an English speaking population. In Anales de psicología 26:2 [online]. https:/www.drake.edu/media/departmentsoffices/dusci/pdfdocuments/Psychometric-CREA.pdf (accessed 15 July 2017)

Corbalán Berna, Javier/Martínez Zaragoza, Fermín/Donolo, Danilo/Monreal, Carlos Alonso/Tejerina Arreal, María/ Limiñana Gras, Rosa María 2003: CREA. Inteligencia Creativa. Una medida cognitiva de la creatividad. Madrid: TEA Ediciones.

Damasio, Antonio 1994: Descartes'Error: Emotion, Reason and the Human Brain. New York: Avon Books.

Damasio, Antonio 2010: Self Comes to Mind: Constructing the Conscious Brain. New York: Pantheon Books.

Dragsted, Barbara/Hansen, Inge Gorm/Sørensen, Henrik Selsøe 2009: Experts exposed. In Mees Inger/Alves, Fabio/ Göpferich, Susanne (eds.) Methodology, Technology and Innovation in Translation Process Research. Copenhagen: Samfundslitteratur, 293-317.

Ericsson, K. Anders 1998: The scientific study of expert levels of performance: General implications for optimal learning and creativity. In High Ability Studies: The Journal of the European Council for High Ability 9:1, 75-100.

Frensch, Peter A./Sternberg, Robert J. 1989: Expertise and intelligence thinking: When is it worse to know better? In Sternberg, Robert J. (ed.), Advances in the Psychology of Human Intelligence. Hillsdale, NJ: Erlbaum, 157-188.

Gabora, Liane 2010: Revenge of the 'neurds': Characterizing creative thought in terms of the structure and dynamics of human memory. In Creativity Research Journal 22:1, 1-13.

Gerrard, Lara Edwards/Poteat, G.Michael/Itonsmith, Marsha 1996: Promoting childen's creativity: Effects of competition, self-esteem and immunization. In Creativity Research Journal 9:4, 339-346.

Guilford, Joy Paul 1950: Creativity. In American Psychologist 5:9, 444-454.

Guilford, Joy Paul 1956: The structure of intellect. In Psychological Bulletin 53:4, 267-293.

Heiden, Tanja 2005: Blick in die Black Box: Kreative Momente im Übersetzungsprozess: eine experimentelle Studie mit Translog. In Meta 50:2, 448-472.

Hubscher-Davidson, Severine 2009: Personal diversity and diverse personalities in translation: A study of individual differences. In Perspectives: Studies in Translatology 17:3, 175-192. 
Hubscher-Davidson, Severine 2013a: The role of intuition in the translation process: A case study. In Translation and Interpreting Studies 8:2, 211-232.

Hubscher-Davidson, Severine 2013b: Emotional Intelligence and Professional Translation. Paper presented at the International Online Workshop on Affective factors in Translation Process Research: To Feel or not to Feel? That is the Question, Aston University.

Hubscher-Davidson, Severine 2013c: Emotional intelligence and translation studies: A new bridge. In Meta 58:2, 324346.

Jaarsveld, Saskia/Lachmann, Thomas 2017: Intelligence and Creativity in Problem Solving: The Importance of Test Features in Cognition Research. In Frontiers in Psychology 8 [online]. https://www.ncbi.nlm.nih.gov/pmc/articles/ PMC5292426/ (accessed 25 July 2017).

Jauk, Emanuel/Benedek, Mathias/Dunst, Beate/Neubauer, Aljoscha C. 2013: The relationship between intelligence and creativity: New support for the threshold hypothesis by means of empirical breakpoint detection. In Intelligence 41:4, 212-221.

Jaussi, Kimberly S./Randell, Amy E./Dionne, Shelley D. 2007: I am, I think I can, and I do: The role of personal identity, self-efficacy, and cross-applications of experiences in creativity at work. In Creativity Research Journal 19:2-3, 247-258.

Kussmaul, Paul 2000a: A cognitive framework for looking at creative mental processes. In Olohan, Maeve (ed.), Intercultural Faultlines: Research Models in Translation Studies I: Textual and Cognitive Aspects. Manchester: St. Jerome, 59-71.

Kussmaul, Paul 2000b: Types of creative translating. In Chesterman, Andrew/San Salvador, Natividad Gallardo/Gambier, Yves (eds.), Translation in Context: Selected Papers from the EST Congress, Granada 1998. Amsterdam/ Philadelphia: Benjamins, 117-126.

Martindale, Colin/Hasenfus, Nancy 1978: EEG differences as a function of creativity, stage of the creative process, and effort to be original. In Biological Psychology 6 157-167.

Mueller, Jennifer S./Melwani, Shimul/Goncalo, Jack A. 2010: The bias against creativity: Why people desire but reject creative ideas [online]. http://digitalcommons.ilr.cornell.edu/articles/450/ (accessed 16 March 2017).

Nord, Christiane 1977: Translation as a Purposeful Activity. Manchester: St. Jerome.

Oakley, Todd 1996: From Attention to Meaning. Explorations in Semiotics, Linguistics and Rhetoric. Berlin and New York: Peter Lang.

Perteghella, Manuela/Loffredo, Eugenia 2006: Translation and Creativity. Perspectives on Creative Writing and Translation Studies. London/New York: Continuum.

Pratchett, Terry 1991: Witches Abroad. London: Corgi.

Ramos, Marina/Rojo, Ana 2016: Analysing the AD process: creativity, expertise and quality. Paper presented at the $8^{\text {th }}$ EST Conference Translation Studies - Moving Boundaries, Aarhus University, Denmark.

Reilly, Rosemary C. 2008: Is expertise a necessary precondition for creativity?: A case of four novice learning group facilitators. In Thinking Skills and Creativity 3:1, 59-76.

Riccardi, Alessandra 1998: Interpreting strategies and creativity. In Beylard-Ozeroff, Ann/Králová, Jana/Moser-Mercer, Barbara (eds.), Translator's Strategies and Creativity. Selected Papers from the 9th International Conference on Translation and Interpreting. Amsterdam/Philadelphia, 171-179.

Rojo, Ana/Ramos, Marina 2016: Can emotion stir translation skill? Defining the impact of positive and negative emotions on translation performance. In Muñoz Martín, Ricardo (ed.), Reembedding Translation Process Research. Amsterdam/ Philadelphia: Benjamins, 107-130.

Rojo, Ana/Ramos, Marina (in press): The role of expertise in emotion regulation: Exploring the effect of expertise on translation performance under emotional stir. In La Cruz, Isabel/Jääskeläinen, Riitta (eds.), New Directions in Cognitive and Empirical Translation Process Research. Amsterdam/Philadelphia: Benjamins.

Silvia, Paul J./Kaufman, James C./Pretz, Jean E. 2009: Is creativity domain-specific? Latent class models of creative accomplishments and creative self-descriptions. In Psychology of Aesthetics, Creativity, and the Arts 3:3, 139-148.

Stenberg, Robert J. 2006: The nature of creativity. In Creativity Research Journal 18:1, 87-98.

Tiselius, Elisabet/Jenset, B. Gard 2011: Process and product in simultaneous interpreting: What it tells us about experience and expertise. In Alvstad, Cecilia/Hild, Adelina/Tiselius, Elisabet (eds.), Methods and Strategies of Process Research Integrative Approaches in Translation Studies. Amsterdam/Philadelphia: Benjamins, 269-300.

Vartanian, Oshin/Martindale, Colin/Kwiatkowski, Jonna 2007: Creative potential, attention, and speed of information processing. In Personality and Individual Differences 43, 1470-1480.

Weisberg, Robert W. 1993: Creativity: Beyond the myth of genius. New York: Freeman. 
Wiley, Jennifer 1998: Expertise as mental set: The effects of domain knowledge in creative problem solving. In Memory and Cognition 26:4, 716-730. 


\section{Appendix 1. CREA test}

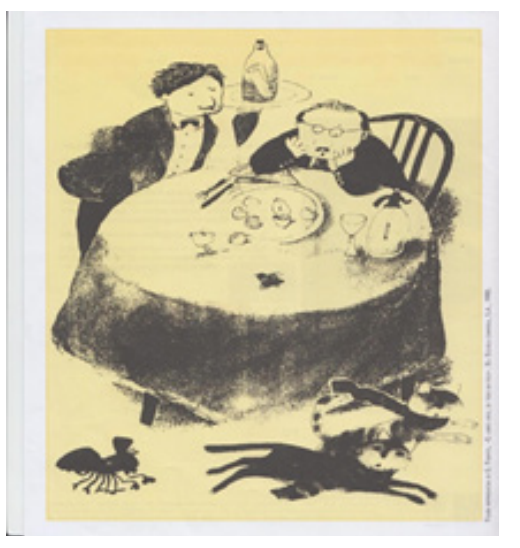

\section{Appendix 2. Extract from Terry Pratchett's novel Witches Abroad (1991: 11)}

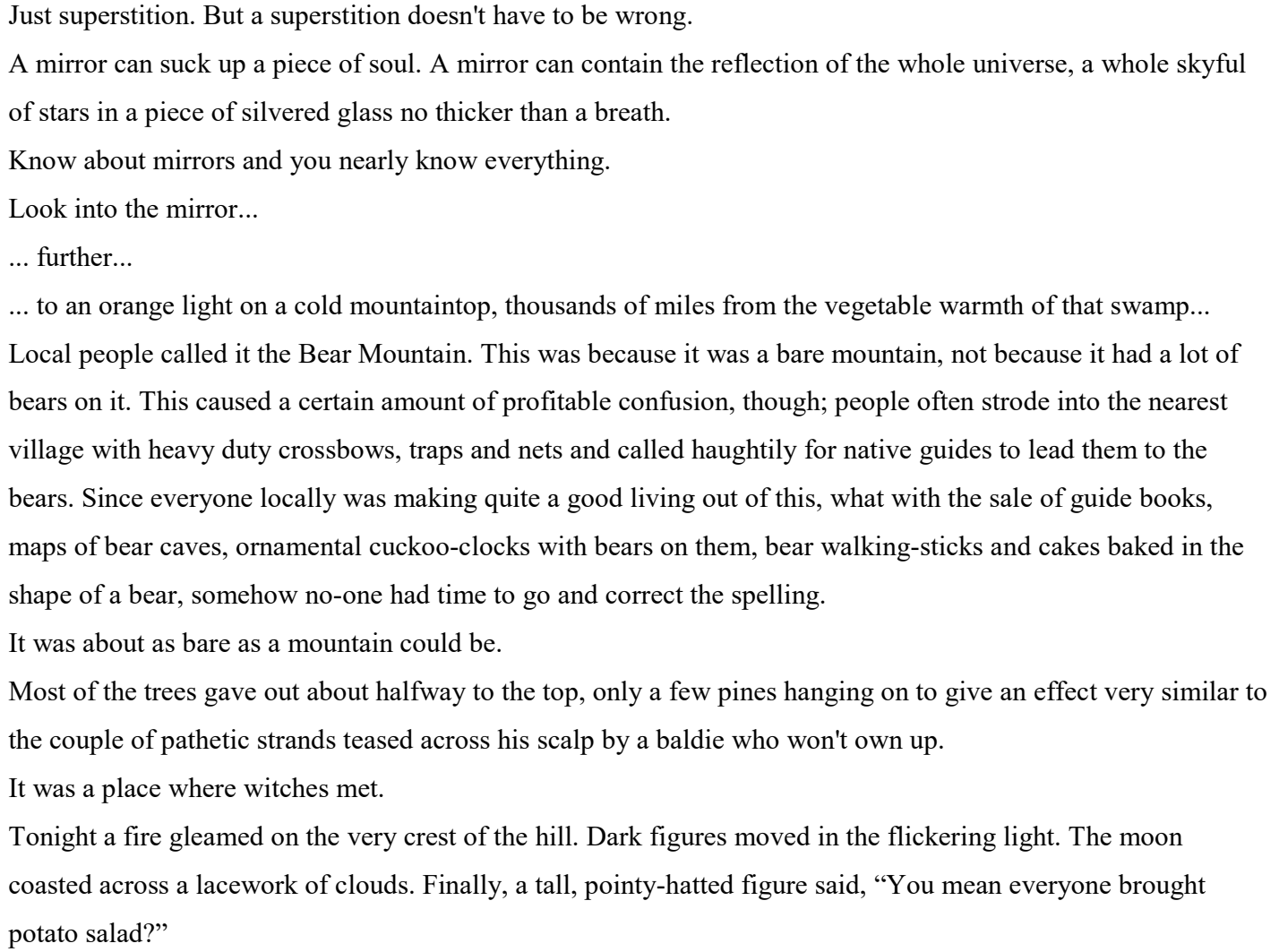


Appendix 3. Correction sheet

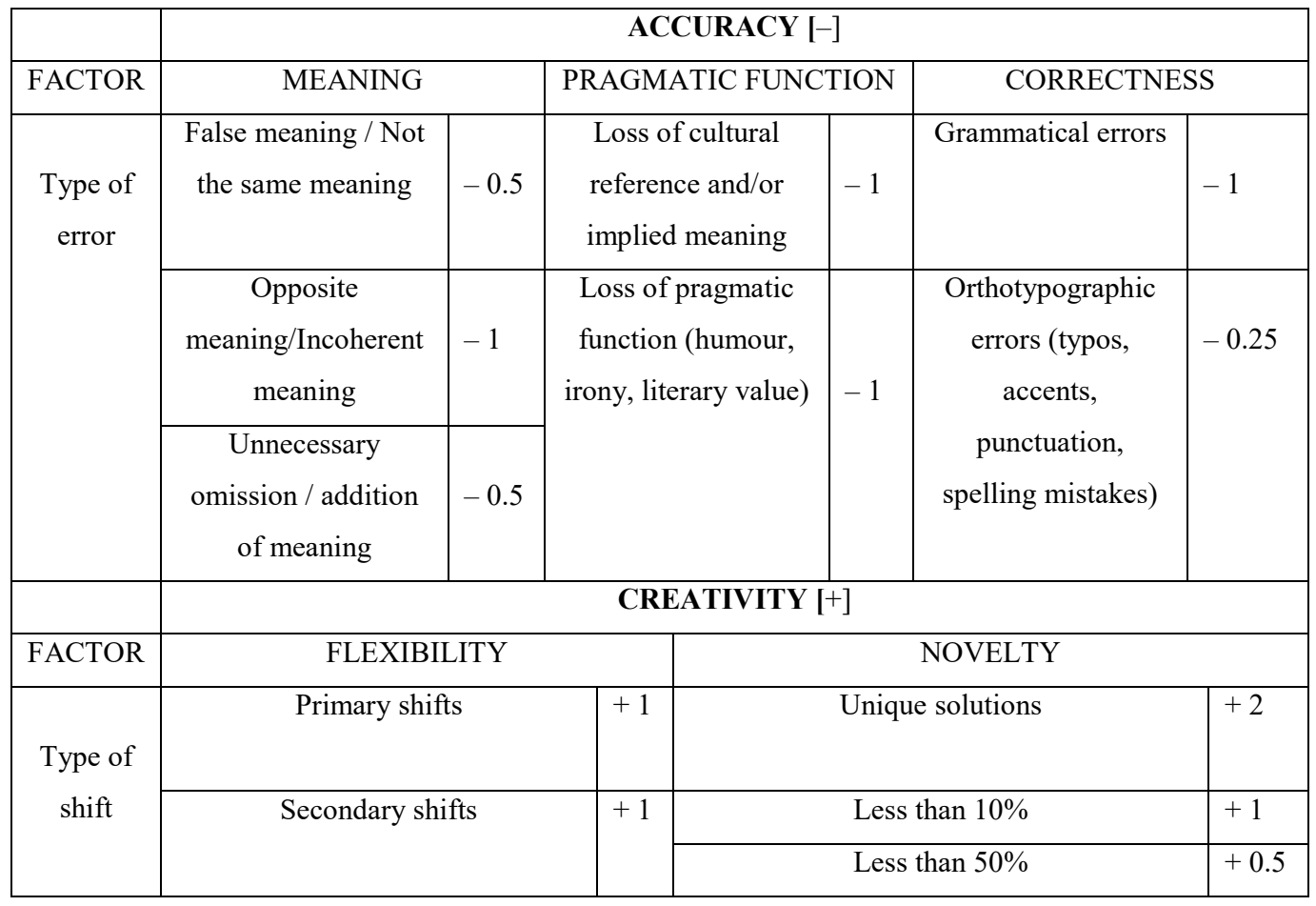

